\title{
Community-weighted mean traits but not functional diversity determine the changes in soil properties during wetland drying on the Tibetan Plateau
}

\author{
Wei Li ${ }^{1,2}$, Howard E. Epstein ${ }^{3}$, Zhongming Wen ${ }^{1,2}$, Jie Zhao ${ }^{4}$, Jingwei Jin ${ }^{1,2}$, Guanghua Jing ${ }^{2}$, Jimin Cheng ${ }^{1,2}$, and \\ Guozhen Du ${ }^{5}$ \\ ${ }^{1}$ State Key Laboratory of Soil Erosion and Dryland Farming on the Loess Plateau, Northwest A\&F University, \\ Yangling 712100, China \\ ${ }^{2}$ Institute of Soil and Water Conservation of Chinese Academy of Sciences \& Ministry of Water Resource, \\ Yangling 712100, China \\ ${ }^{3}$ Department of Environmental Sciences, University of Virginia, 291 McCormick Road, Charlottesville, \\ VA 22904-4123, USA \\ ${ }^{4}$ College of Animal Science and Technology, Northwest A\&F University, Yangling 712100, China \\ ${ }^{5}$ School of Life Sciences, Lanzhou University, Lanzhou 730000, China
}

Correspondence to: Wei Li (liwei2013@nwsuaf.edu.cn)

Received: 5 November 2016 - Published in Solid Earth Discuss.: 16 November 2016

Revised: 16 December 2016 - Accepted: 8 January 2017 - Published: 6 February 2017

\begin{abstract}
Climate change and human activities have caused a shift in vegetation composition and soil biogeochemical cycles of alpine wetlands on the Tibetan Plateau. The primary goal of this study was to test for associations between community-weighted mean (CWM) traits, functional diversity, and soil properties during wetland drying. We collected soil samples and investigated the aboveground vegetation in swamp, swamp meadow, and typical meadow environments. Four CWM trait values (specific leaf area is SLA, leaf dry matter content is LDMC, leaf area is LA, and mature plant height is MPH) for 42 common species were measured across the three habitats; three components of functional diversity (functional richness, functional evenness, and functional divergence) were also quantified at these sites. Our results showed that the drying of the wetland dramatically altered plant community and soil properties. There was a significant correlation between CWM of traits and soil properties, but not a significant correlation between functional diversity and soil properties. Our results further showed that CWM-LA, CWM-SLA, and CWM-LDMC had positive correlations with soil readily available nutrients (available nitrogen, AN; available phosphorus, AP), but negative correlations with total soil nutrients (soil organic carbon is SOC,
\end{abstract}

total nitrogen is TN, and total phosphorus is TP). Our study demonstrated that simple, quantitative plant functional traits, but not functional diversity, are directly related to soil $\mathrm{C}$ and $\mathrm{N}$ properties, and they likely play an important role in plant-soil interactions. Our results also suggest that functional identity of species may be more important than functional diversity in influencing ecosystem processes during wetland drying.

\section{Introduction}

About one-third of China's natural wetlands are situated on the Tibetan Plateau, according to a state-of-the-art remotesensing based classification (Gong et al., 2010). The wetlands of Maqu on the Tibetan Plateau are one of the highest wetlands, and they play a very important role in water resource conservation and in regulating the river systems and regional climates across the entire Yellow River basin (Cai and Guo, 2007). However, these wetlands are also climatesensitive and have been gradually shrinking and drying due to climate change and human activities, such as heavy grazing and land use changes (Cai and Guo, 2007; Peng et al., 
2015; Wang et al., 2016). Hence, it is imperative that we examine the changes in vegetation and soil and the relationships between them during this process of wetland drying for prediction and conservation efforts.

Previous studies have suggested that there may be a secondary successional change from swamp to swamp meadow and mature meadow and that soil water availability may be the main driver of this successional process (Ma et al., 2014; He and Richards, 2015; Lin et al., 2015). At the same time, plant functional traits play an important role in predicting the patterns of species composition, community structure, and their responses to environment change, which has drawn substantial ecological interest (e.g., Wright et al., 2004; McGill et al., 2006; Pérez et al., 2014; Li et al., 2015a); however, it is not clear whether functional traits and functional diversity (i.e., the identity, abundance, and range of species in a given community) can reflect the changes in soil properties during wetland drying on the Tibetan Plateau. A growing body of evidence has shown that functional diversity is directly linked with ecosystem processes (McGill et al., 2006; Flynn et al., 2011). However, recent studies have shown that environmental disturbance (e.g., fertilization or grazing) does not influence functional diversity (Li et al., 2015a; Niu et al., 2015), and functional traits of species may be more important than functional diversity in influencing ecosystem processes in an alpine meadow community (Li et al., 2015a).

Since the relationships between the plant community and environmental factors are dynamic, certain traits may be used to predict the changes in environmental factors (Lavorel and Garnier, 2002; Suding et al., 2008). At the species scale, some leaf traits that respond to water or nutrient availability (e.g., leaf dry matter content is LDMC and leaf nitrogen content is LNC) also affect leaf palatability and litter decomposability (Diaz et al., 2004). Similarly, at the community scale, the community-level means of some functional traits (e.g., specific leaf area (SLA), leaf area (LA), LDMC or plant height) weighted by their relative abundances can respond to environmental change in grasslands and affect nutrient cycling and dynamics (Garnier et al., 2004; Quétier et al., 2007).

The "mass ratio hypothesis" proposed by Grime (1998) implies that the functioning of ecosystems is determined to a large extent by the trait values of the dominant species. This hypothesis was confirmed by some studies that account for ecosystem functions such as primary productivity (Garnier et al., 2004) and nitrification (Laughlin, 2011). Conversely, the "diversity hypothesis" postulates that the trait diversity within a community can affect ecosystem processes (Tilman, 1997). The high functional diversity may allow for a more complete use of resources among species, thereby increasing biomass production and nutrient retention in ecosystems (Loreau, 2000; Díaz and Cabido, 2001; Villéger et al., 2008; Mouchet et al., 2010). The plant functional traits selected therefore pertain to the processing of resources at the species level, with the underlying assumption that this would scale up to ecosystem functioning (Lavorel and Garnier, 2002). We chose four functional traits, known to affect nutrient cycles at the leaf, whole-plant, and ecosystem levels (Cornelissen et al., 1999; Lavorel and Garnier, 2002): SLA (the ratio of water-saturated leaf area to leaf dry mass), LDMC (the ratio of leaf dry mass to water-saturated fresh mass), LA, and mature plant height (MPH). SLA is an important variable in comparative plant ecology because it is closely related to relative growth rate (Wright et al., 2001) and leaf net assimilation rate (Shipley and Lechowicz, 2000); it is also a good predictor of plant response to resource availability (Grime, 1977). LDMC is tied to plant nutrient retention and water (Poorter and Garnier, 1999). LA has important consequences for the leaf energy and water balance (Cornelissen et al., 2003). MPH has been associated with competitive ability in herbaceous plant communities, with the general idea that light competition becomes more intense at high soil fertility when aboveground biomass or vegetation stature increases (Hautier et al., 2009). Fast-growing species from nutrient-rich habitats usually have high SLA, high LNC, and low LDMC, while opposite trends characterize species from nutrient-poor habitats (Diaz et al., 2004). These responses reflect a fundamental trade-off (leaf economics spectrum) between traits related to nutrient conservation and traits related to nutrient acquisition and turnover (Wright et al., 2004).

In this study, we investigate whether soil properties are affected by plant functional traits and functional diversity during wetland drying. Ongoing extensification of human activities has affected the functional composition and structure of wetlands on the Tibetan Plateau (Cai and Guo, 2007; Peng et al., 2015). At the same time, the soil nutrient availability has also been modified (Robson et al., 2007), and this has been directly linked to community-level trait changes in response to environmental dynamics (Diaz et al., 2007). The aim of this study was to answer the following questions: (1) How do community composition and structure and soil nutrient characteristics change following wetland drying on the Tibetan Plateau? (2) Can the community-weighted mean (CWM) trait values and functional diversity be regarded as predictors of soil properties during wetland drying?

\section{Materials and methods}

\subsection{Study site}

This study was conducted at the Research Station of Alpine Meadow and Wetland Ecosystems of Lanzhou University $\left(33^{\circ} 58^{\prime} \mathrm{N}, 101^{\circ} 53^{\prime} \mathrm{E}\right.$; Fig. 1). The site is located on the eastern Tibetan Plateau. The mean annual temperature is $1.2^{\circ} \mathrm{C}$, ranging from -10 in January to $11.7^{\circ} \mathrm{C}$ in July, and the mean annual precipitation (calculated from 1975 to 2010) was $620 \mathrm{~mm}$, occurring mainly during the short, cool summer (Li et al., 2011a). The annual duration of cloud-free solar radiation is about $2580 \mathrm{~h}$, and there are on average 270 
Table 1. Brief descriptions for vegetation properties (species richness, vegetation cover, aboveground biomass, and dominant species), grazing intensity, and standing water status during the wetland drying. Swamp is S, swamp meadow is SM, and typical meadow is TM. Significant differences across treatments within each variable were determined using Tukey's honest significant difference test $(P<0.05)$ after one-way analysis of variance and are indicated by dissimilar letters.

\begin{tabular}{|c|c|c|c|c|c|c|}
\hline Types & $\begin{array}{l}\text { Species richness } \\
\left(\text { no. } 0.25 \mathrm{~m}^{-2}\right)\end{array}$ & $\begin{array}{l}\text { Vegetation } \\
\text { cover }(\%)\end{array}$ & $\begin{array}{r}\text { Aboveground biomass } \\
\left({\left.\mathrm{g} 0.25 \mathrm{~m}^{-2}\right)}\right.\end{array}$ & Dominant species & Grazing intensity & Standing water status \\
\hline $\mathrm{S}$ & $7.9(1.85) \mathrm{c}$ & $72.3 \%(13.12 \%) b$ & $56.9(10.84) \mathrm{c}$ & $\begin{array}{l}\text { Deschampsia caespi- } \\
\text { tosa, Carex meyeriana, } \\
\text { Blysmus sinocompres- } \\
\text { sus, Nardostachys } \\
\text { jatamansi, Caltha } \\
\text { palustris }\end{array}$ & $\begin{array}{l}\text { Lightly grazed by } \\
\text { livestock (yak and } \\
\text { Tibetan sheep). }\end{array}$ & $\begin{array}{l}\text { It was dry for most } \\
\text { of the year, with about } \\
4 \text { months (July to Octo- } \\
\text { ber) with standing water } \\
\text { during the rainy season. }\end{array}$ \\
\hline SM & $14.2(1.98) b$ & $71.3 \%(9.23 \%) \mathrm{b}$ & $97.6(8.66) \mathrm{b}$ & $\begin{array}{l}\text { Nardostachys jatamansi, } \\
\text { Deschampsia caespi- } \\
\text { tosa, Caltha palustris, } \\
\text { Rumex patientia, San- } \\
\text { guisorba filiformis, } \\
\text { Cremanthodium lineare }\end{array}$ & $\begin{array}{l}\text { Grazing distur- } \\
\text { bance by Tibetan } \\
\text { sheep and yak was } \\
\text { higher than that in } \\
\text { swamp. }\end{array}$ & $\begin{array}{l}\text { No standing water at any } \\
\text { time for the whole year. }\end{array}$ \\
\hline TM & 20.7 (1.77)a & $88.5 \%(12.17 \%) a$ & $124.4(11.27) \mathrm{a}$ & $\begin{array}{l}\text { Kobresia capilifolia, } \\
\text { Elymus nutans, Poa } \\
\text { poophagorum, Koeleria } \\
\text { cristata, Anemone rivu- } \\
\text { laris, Trollius farreri, } \\
\text { Festuca ovina }\end{array}$ & $\begin{array}{ll}\text { Grazing } & \text { distur- } \\
\text { bance was } & \text { similar } \\
\text { to swamp } & \\
\text { meadow. } & \end{array}$ & $\begin{array}{l}\text { No standing water at any } \\
\text { time for the whole year. }\end{array}$ \\
\hline
\end{tabular}

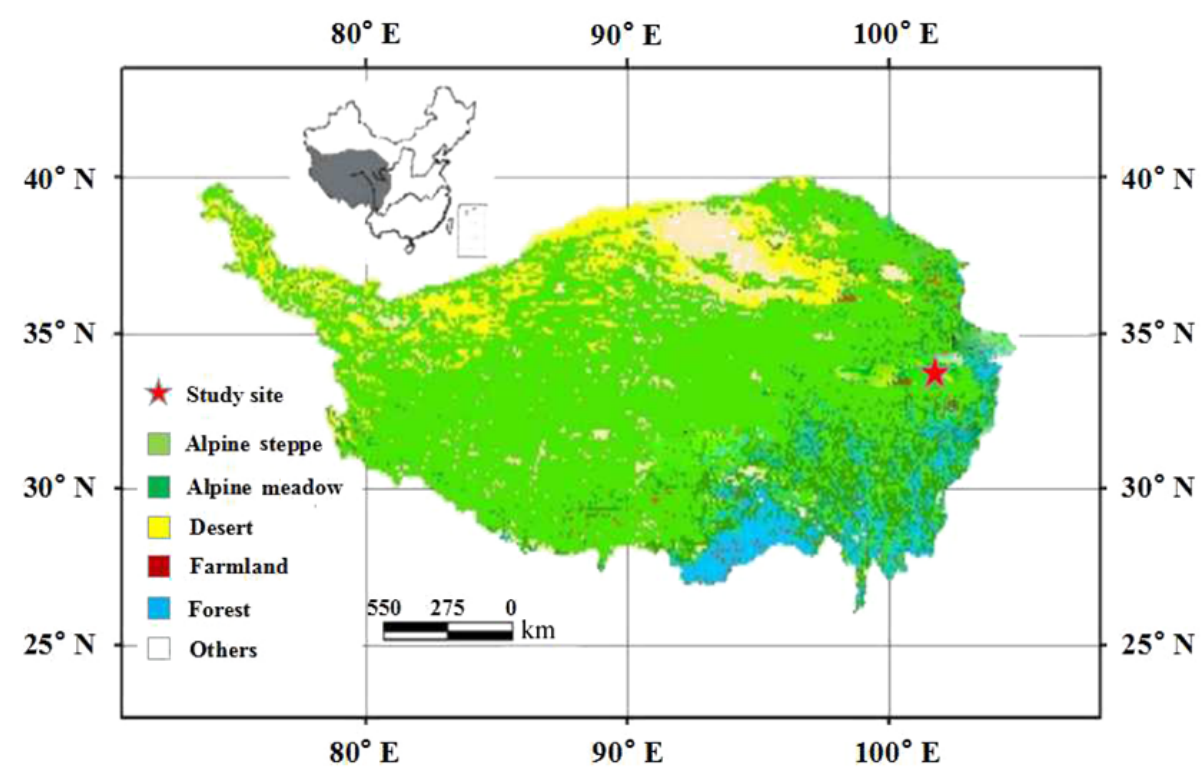

Figure 1. The location of the Tibetan Plateau in China and our study site (the Research Station of Alpine Meadow and Wetland Ecosystems of Lanzhou University) at the Tibetan Plateau.

frost days per year. The soil type of the study area is alpine meadow soil. Parent materials are from a variety of glacial deposits, alluvial deposits, residual deposits, residual slope deposits, etc. (Chen and Wang, 1999). The experiment was carried out in a typical mature meadow, swamp meadow, and swamp, which are adjacent to each other in our study area. These habitats have different community compositions, structures, and dominant species (Table 1).

\subsection{Experimental design and community measurements}

In each meadow type, 25 sampling plots $(10 \mathrm{~m} \times 8 \mathrm{~m})$ were selected. Each plot was separated from the others by a $2 \mathrm{~m}$ buffer strip. Each plot was separated into two subplots: a $4 \mathrm{~m} \times 8 \mathrm{~m}$ subplot for community investigation and soil collection and a $6 \mathrm{~m} \times 8 \mathrm{~m}$ subplot for individual plant sampling. Community measurements were conducted from 5 to 
8 September 2010 . One $0.25 \mathrm{~m}^{2}$ quadrat was harvested from the $4 \mathrm{~m} \times 8 \mathrm{~m}$ subplot in each plot. The quadrat location was randomly selected with the constraint that it was at least $0.5 \mathrm{~m}$ from the margin to avoid edge effects. We estimated the cover of each species and vegetation before it was clipped and brought to the lab. For clonal species, an individual plant was defined as a group of tillers connected by a crown (Luo et al., 2006). The cover of each species in each plot was estimated as a percentage, using a canopy interception technique based on cardboard cutouts of various shapes and sizes as visual guides. All samples were dried at $80^{\circ} \mathrm{C}$ for $48 \mathrm{~h}$ and weighed to the nearest $0.01 \mathrm{~g}$. Aboveground biomass was calculated by summing all dried biomass of harvested individuals within a quadrat.

\subsection{Soil collection and processing}

Soil samples $(0-15 \mathrm{~cm}$ depth) were collected from each quadrat in each sampling plot of each habitat after the aboveground material was harvested. In each quadrat, soil was randomly collected from three points ( $3.8 \mathrm{~cm}$ in diameter) using a bucket auger and mixed into a single soil sample. All of the soil samples were brought into the laboratory in airtight plastic bags. All of the soil samples were air-dried and then filtered through a $0.2 \mathrm{~mm}$ sieve, discarding the visible roots and other plant debris. Soil $\mathrm{pH}$ was measured using a $\mathrm{pH}$ meter with a glass electrode (soil / $\mathrm{KCl}$ ratio is $1: 2.5$ ). Soil water content was obtained using the oven-drying method. Soil organic carbon was determined using the Walkley-Black method and a factor of 1.3 was applied to adjust the organic C recovery (Nelson and Sommers, 1982). The soil total nitrogen, available nitrogen, total phosphorus, and available phosphorus were measured using the methods of Miller and Keeney (1982).

\subsection{Plant functional trait measurements}

Following Perez-Harguindeguy et al. (2013), we measured four functional traits (SLA, LDMC, LA, and MPH) of 42 common species for three habitats in early September 2010. These species represented $85-95 \%$ of the peak standing biomass and $80-90 \%$ of the vegetation cover of the total plant community in the studied plots. We randomly sampled one individual and three mature leaves at flowering time for each of the 42 species in each $6 \mathrm{~m} \times 8 \mathrm{~m}$ subplot. That is, 25 individuals and 75 mature leaves were measured for each of the 42 species in each habitat. MPH is the shortest distance between the upper foliage boundary and ground level. Leaves were scanned to measure leaf area in the field, and fresh weight of leaves was determined with a balance (Acculab Lt-320; Acculab Measurement Standards Inc., Danvers, MA, USA). Following these measurements, leaves were placed in paper bags and dried in the sun. Leaf samples were oven-dried at $80^{\circ} \mathrm{C}$ for $48 \mathrm{~h}$ in the laboratory, and their dry masses were measured on a semi-analytical balance with an accuracy of $10^{-4} \mathrm{~g}$ (Sartorius AG, Göttingen, Germany).

\subsection{Statistical analysis}

From the vegetation harvest data, we calculated the species richness (Pielou, 1969), represented by the number of species recorded in each quadrat. Following Garnier et al. (2004), CWM trait values for each trait were calculated for every sample using species mean trait values and species relative cover: $\mathrm{CWM}=\sum_{i=1}^{S} P_{i} \times$ trait $_{i}$, where $S$ is species richness, $P_{i}$ is the proportional cover of species $i$, and trait ${ }_{i}$ is the trait value of species $i$.

Although various indices have been proposed to measure the functional diversity of a community, there is still no consensus on which are most suitable. Villéger et al. (2008) suggested that some of the indices of functional diversity are redundant and they recommended using three independent components of functional diversity: functional richness (FRic), functional evenness (FEve), and functional divergence (FDiv). In this study, we chose FRic, FEve, and FDiv to examine how different components of functional diversity responded to different habitat types. We used the FDiversity software program to calculate FRic, FEve, and FDiv after the traits were standardized to ensure equal contributions from each trait.

We used one-way analysis of variance (ANOVA) to test the effect of different habitat types on plant taxonomic diversity (species richness), the CWM traits, functional diversity (FRic, FEve, and FDiv), and soil properties. Correlations between the CWM traits and soil properties were tested using Pearson's correlation coefficients, and a principal components analysis (PCA) on standardized data was conducted to analyze the overall pattern of correlations between soil properties, functional diversity, and aggregated trait values. These statistical analyses were performed using the R 3.2.3 software (R Development Core Team, 2011).

\section{Results and analysis}

\subsection{Vegetation response}

Wetland drying had obvious effects on vegetation composition and structure, and our study demonstrated that the species richness, vegetation cover, and aboveground biomass significantly increased with wetland drying (Table 1). There were also significant differences in species composition among the community types (Table 1). Many typical wetland plants gradually disappeared from the vegetation after wetland drying occurred; these included Carex meyeriana, Blysmus sinocompressus, Rumex patientia, Nardostachys jatamansi, Caltha palustris, Sanguisorba filiformis, and Cremanthodium lineare. Others greatly decreased in abundance, mainly Deschampsia caespitosa. Meanwhile, many other 
Table 2. Relationships between CWM traits and soil properties from a Pearson's correlation analysis.

\begin{tabular}{|c|c|c|c|c|c|c|c|}
\hline & $\begin{array}{r}\text { Soil organic } \\
\text { carbon } \\
\left(\mathrm{g} \mathrm{kg}^{-1}\right)\end{array}$ & $\begin{array}{l}\text { Soil total } \\
\text { nitrogen } \\
\left(\mathrm{g} \mathrm{kg}^{-1}\right)\end{array}$ & $\begin{array}{r}\text { Soil total } \\
\text { phosphorus } \\
\left(\mathrm{g} \mathrm{kg}^{-1}\right)\end{array}$ & $\begin{array}{r}\text { Soil available } \\
\text { nitrogen } \\
\left(\mathrm{mg} \mathrm{kg}^{-1}\right)\end{array}$ & $\begin{array}{r}\text { Soil available } \\
\text { phosphorus } \\
\left(\mathrm{mg} \mathrm{kg}^{-1}\right)\end{array}$ & $\begin{array}{r}\text { Soil moisture } \\
(\%)\end{array}$ & $\begin{array}{r}\text { Soil pH } \\
\text { value }\end{array}$ \\
\hline $\begin{array}{l}\text { CWM-SLA } \\
\left(\mathrm{cm}^{2} \mathrm{~g}^{-1}\right)\end{array}$ & $-0.805^{* *}$ & $-0.781^{* *}$ & $-0.364^{*}$ & $0.485^{*}$ & $0.730^{* *}$ & $-0.844^{* *}$ & $0.733^{* *}$ \\
\hline $\begin{array}{l}\text { CWM-LDMC } \\
\left(\mathrm{gg}^{-1}\right)\end{array}$ & $-0.803^{* *}$ & $-0.735^{* *}$ & $-0.778^{* *}$ & $0.764^{* *}$ & $0.771^{* *}$ & $-0.815^{* *}$ & $0.748^{* *}$ \\
\hline $\begin{array}{l}\text { CWM-LA } \\
\left(\mathrm{cm}^{2}\right)\end{array}$ & $-0.428^{*}$ & $-0.602^{* *}$ & $-0.312^{*}$ & $0.628^{* *}$ & $0.624^{* *}$ & $-0.710^{* *}$ & $0.696^{* *}$ \\
\hline $\begin{array}{l}\text { CWM-MPH } \\
(\mathrm{cm})\end{array}$ & $0.573^{*}$ & $0.453^{*}$ & $0.464^{* *}$ & $-0.395^{*}$ & $-0.538^{* *}$ & $0.530^{* *}$ & $-0.494^{*}$ \\
\hline $\begin{array}{l}\text { Functional } \\
\text { richness }\end{array}$ & -0.331 & -0.274 & -0.321 & 0.216 & 0.187 & -0.377 & 0.038 \\
\hline $\begin{array}{l}\text { Functional } \\
\text { evenness }\end{array}$ & -0.272 & -0.283 & -0.367 & 0.239 & 0.221 & -0.339 & 0.201 \\
\hline $\begin{array}{l}\text { Functional } \\
\text { divergence }\end{array}$ & -0.318 & -0.248 & -0.379 & 0.313 & 0.312 & -0.299 & 0.04 \\
\hline
\end{tabular}

CWM is community-weighted mean trait values, SLA is leaf area per unit dry mass, LDMC is leaf dry matter content, LA is leaf area, and MPH is mature plant height. ${ }^{*} p<0.05 .{ }^{* *} p<0.01$.

new species emerged from the typical meadow, such as Kobresia capilifolia, Poa poophagorum, Festuca ovina, and Anemone rivularis, all adapted to a high drought environment.

\subsection{Community-weighted means of traits and functional diversity response}

Community-weighted means of traits differed greatly between the three habitats. The CWM-LA, CWM-SLA, and CWM-LDMC significantly increased with wetland drying (Fig. 2a, b, and c); however, the CWM-MPH of swamp (Fig. 2d) was significantly higher than swamp meadow and typical meadow. Functional richness (Fig. 3a), functional evenness (Fig. 3b), and functional divergence (Fig. 3c) had no obvious changes with wetland drying. These results also showed that community-level trait responses (communityweighted means of traits and functional diversity) were completely different, and the single-trait-level responses may be more sensitive than multi-trait-level responses to the process of wetland drying.

\subsection{Soil response}

Wetland drying had obviously different effects on different soil characteristics. Soil organic carbon (SOC, Fig. 4a), soil total nitrogen (TN, Fig. 4b), soil total phosphorus (TP, Fig. 4c), and soil moisture (SM, Fig. 4f) of the swamp were significantly greater than swamp meadow and the typical meadow. However, soil available nitrogen (AN, Fig. 4d), soil available phosphorus (AP, Fig. 4e), and soil pH (Fig. 4g) of the swamp were significantly lower than those of swamp meadow and the typical meadow. These results clearly demonstrated that the changes in soil readily available nutrients (AN and AP) and total soil nutrients (SOC, TP, and TP) may be habitat-dependent, and the soil water content may be the dominant driving factor in the wetland drying.

\subsection{Relationships among CWM traits, functional diversity, and soil properties}

Simple correlations and a PCA combining data on soil properties, community functional diversity, and the CWM traits were conducted. The analyses revealed a significant correlation between soil properties and CWM of traits but not a significant correlation between soil properties and functional diversity (Table 2). Fig. 5 further shows that there were significantly positive correlations between SOC, TN, TP, and SM and CWM-MPH but significantly negative correlations between AN, AP, and pH and CWM-MPH (Table 2, Fig. 5). In contrast, there was a significantly negative correlation between SOC, TN, TP, and SM and CWM-SLA, and CWMLDMC and CWM-LA but significantly positive correlations between AN, AP, and $\mathrm{pH}$ and CWM-SLA, CWM-LDMC, and CWM-LA (Table 2, Fig. 5). In addition, the FRic had a positive relationship with FDiv but a negative relationship with FEve (Fig. 5). Thus, these results showed that community responses of single functional traits may play a crucial role in influencing soil properties during wetland drying. 
$$
\text { है }
$$

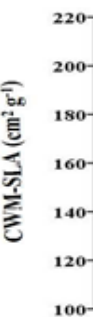
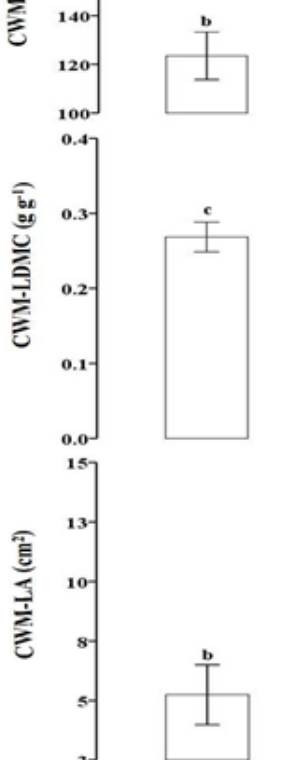

茛 ${ }^{50}{ }^{50}$
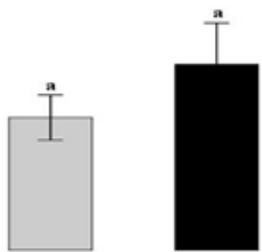

(d)
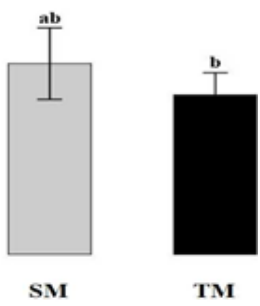

Figure 2. The changes in CWM trait across three habitats. CWM is community-weighted mean trait values, SLA is leaf area per unit dry mass, LDMC is leaf dry matter content, LA is leaf area, MPH is mature plant height, $\mathrm{S}$ is swamp, $\mathrm{SM}$ is swamp meadow, and TM is typical meadow. Significant differences indicated by dissimilar letters above each bar were determined using Tukey's honest significant difference (HSD) test $(P<0.05)$ after one-way ANOVA.

\section{Discussions}

\subsection{Responses of aboveground community composition and functional traits}

Our study demonstrated that species richness, vegetation cover, and aboveground biomass significantly increased with wetland drying and that there were also significant differences in species composition among the community types. Many typical wetland plants disappeared from the community after wetland drying occurred, and many other new species (adapted to a high-drought environment) emerged from the typical meadow.

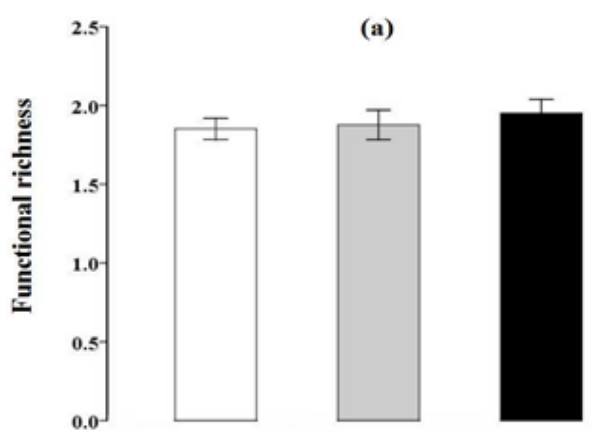

(b)

(c)

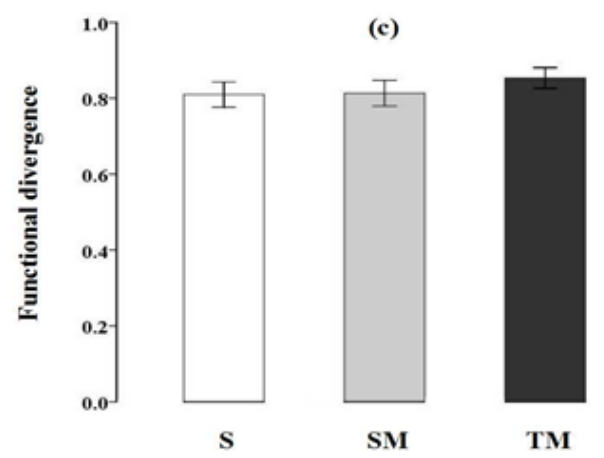

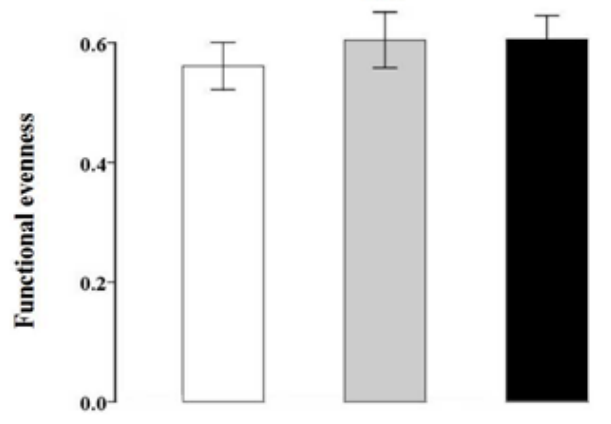

Figure 3. The changes in functional diversity (functional richness, functional evenness, and functional divergence) across three habitats. Significant differences indicated by dissimilar letters above each bar were determined using Tukey's honest significant difference (HSD) test $(P<0.05)$ after one-way ANOVA.

Previous studies have shown that SLA and LA are often closely positively correlated with photosynthesis and transpiration rate (Reich et al., 1999; Westoby et al., 2002), and plants with an exploitative strategy (e.g., high SLA and transpiration rate) are often drought intolerant (Reich et al., 1999; Diaz et al., 2004). Our results also demonstrated that some forb species (e.g., C. palustris, N. jatamansi, and R. patientia; usually with higher SLA and LA) dominated in the swamp meadow. These forb species tended to deplete soil moisture more quickly than grass species, therefore further aggravating the trend of drying for the entire community. Following this, some grass species (e.g., E. nutans, P. poophagorum, and $K$. cristata) with high LDMC would dominate in the typical meadow. Although forb species account for less 


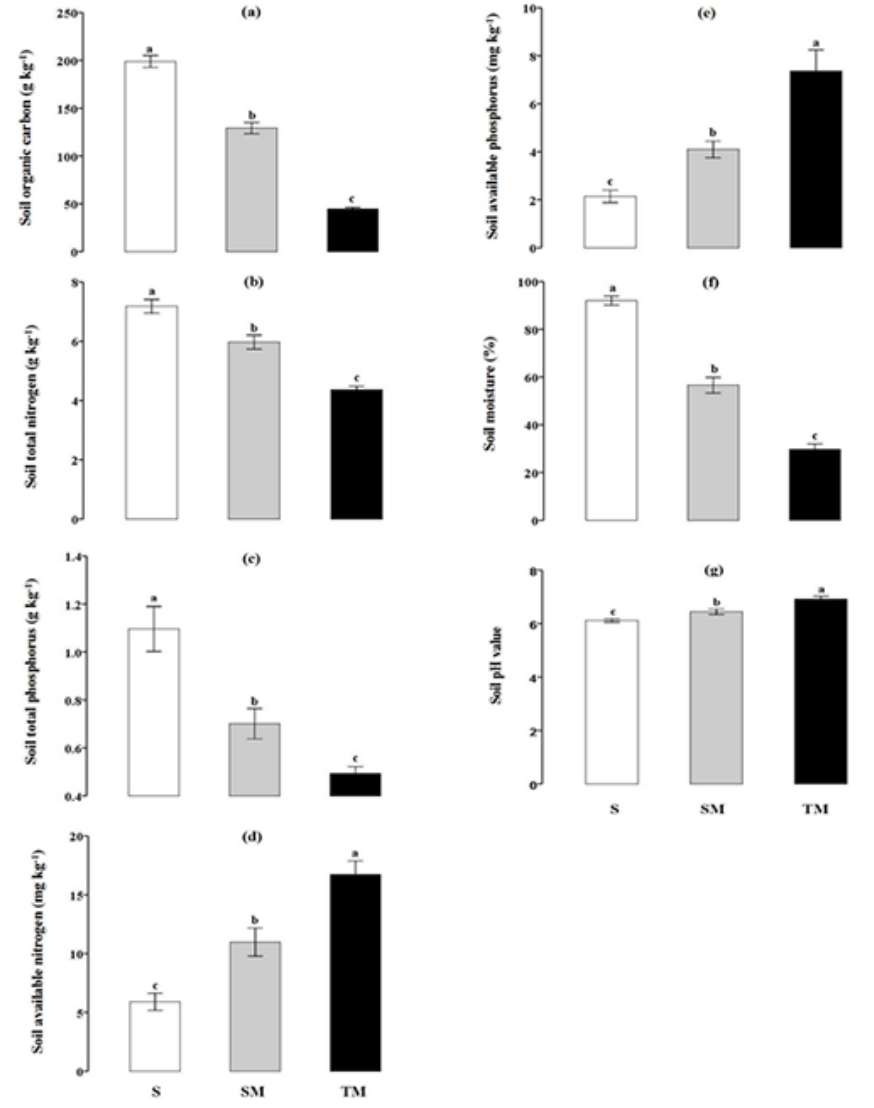

Figure 4. The changes in soil properties across three habitats. $\mathrm{S}$ is swamp, SM is swamp meadow, and TM is typical meadow. Significant differences indicated by dissimilar letters above each bar were determined using Tukey's honest significant difference (HSD) test $(P<0.05)$ after one-way ANOVA.

total biomass than grass species, they formed the bulk of the species diversity in this community, as in most herbaceous communities (Grime, 1998). Plant height has been associated with competitive ability for light interception in herbaceous plant communities, with the general idea that light competition becomes more intense when aboveground biomass or vegetation stature increases (Hautier et al., 2009). In the present study, our results showed that taller plants (e.g., D. caespitosa) dominated in the swamp due to accumulated standing water in summer, but shorter plants dominated in the swamp meadow and typical meadow due to light not being a limiting factor in these communities.

In contrast, functional diversity (FRic, FEve, and FDiv; Fig. 3a ,b, and c) did not show any significant changes among the three habitats (Fig. 3). We speculated that these changes in functional diversity would primarily be determined by the balance between competitive exclusion and stabilizing niche differences (Chesson, 2000; Hille Ris Lambers et al., 2012). Functional diversity may decrease when stabilizing niche differences of species are smaller than are needed to overcome competitive exclusion, and functional diversity may increase

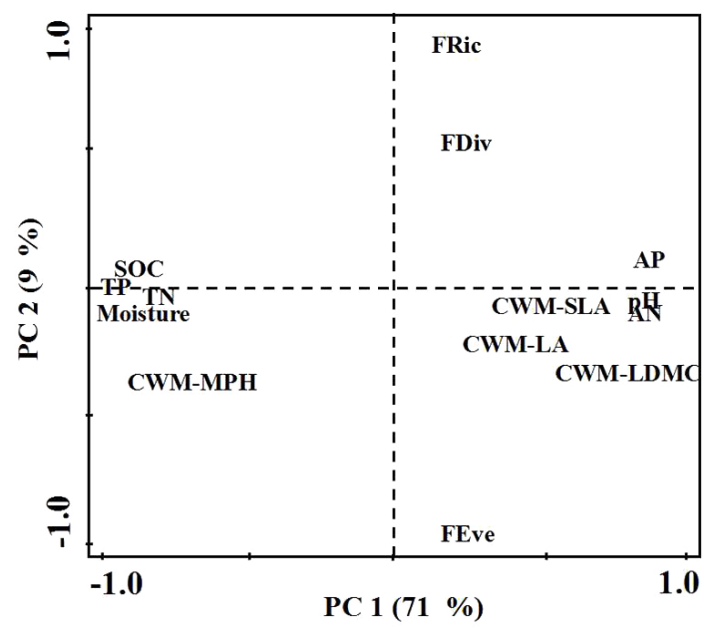

Figure 5. Principal component analysis combining data on soil properties, CWM trait, and functional diversity. Only the first two axes (PC1 and PC2), which account for $80 \%$ of the total variation, are retained here. The first axis can account for $71 \%$ of the total inertia, and it differentiates communities according to soil moisture: the communities of higher soil moisture showed higher SOC, TN, TP, and CWM-MPH, while the communities of lower soil moisture showed higher AN, AP, pH, CWM-LA, CWM-SLA, and CWMLDMC. The second axis can account for $9 \%$ of the total inertia, and it showed that functional richness (FRic) had a positive relationship with functional divergence (FDiv) but a negative relationship with functional evenness (FEve).

when stabilizing niche differences are greater than competitive exclusion. In addition, the responses of functional diversity can be constrained by close functional linkages to any number of traits determining performance at the whole plant level (Reich, 2014). Trade-offs in the responses within a suite of traits can create approximately equal performance at the whole plant level and hence a low value for change in functional diversity (Shipley et al., 2006). These results are consistent with many recent observations that the response of functional diversity to fertilization and grazing are relatively stable (Niu et al., 2015; Li et al., 2015a), and they highlight the potential complexity of community responses to environmental change.

\subsection{Response of belowground soil properties}

Our results showed that the soil of the swamp had significantly higher moisture, organic carbon, total phosphorus, and total nitrogen but lower $\mathrm{pH}$, available nitrogen, and available phosphorus than the swamp meadow and typical meadow. These results indicate that the soil total nutrient content had a decreasing trend with wetland drying. The wetlands can accumulate a large amount of soil organic matter because of lower decomposition rates of litter due to permanent or temporary anaerobiosis associated with waterlogged conditions (Nieder and Benbi, 2008). However, the drying of wetlands 
can stimulate microbial activity and increase mineralization of soil organic matter (Denef et al., 2001), therefore leading to an increase in soil readily available nutrients, such as nitrogen and phosphorus. However, other studies have reported that a reduction in mineralization with drying could be caused by reduced microbial activity and mobility (Pulleman and Tietema, 1999). In swamp meadow and typical meadow, certain factors can contribute to reduced soil total nutrient content. First, trampling by livestock (yak and Tibetan sheep) can lead to compaction and changes in infiltration rates, bulk density, and decline of edaphon activity (Li et al., 2011b; Yu and Jia, 2014). Second, under the long-term pressure of grazing, some energy and nutrients are transferred to livestock ( $\mathrm{Li}$ et al., 2011b; Lu et al., 2015). In addition, the available forms of nitrogen and phosphorus in the wetland are lower than in the typical meadow because they are very water-soluble and move rapidly in the wetland environment.

\subsection{Relationships among CWM traits, functional diversity, and soil properties}

Simple correlations and a PCA analysis strongly support the idea that fast-growing plant species can promote the rates of soil $\mathrm{C}, \mathrm{N}$, and $\mathrm{P}$ cycling, which in turn results in high nutrient availability but relatively low $\mathrm{C}$ and $\mathrm{N}$ sequestration. A striking result of the present study is that aboveground plant traits can determine the changes in belowground soil properties during wetland drying. There are two likely reasons to explain this phenomenon. First, it is possible that high-quality litter results in high decomposition rates in suitable environmental conditions, whereas lower-quality litter might result in a more consistent level of microbial activity due to the longer residence time of the litter in soil. For the swamp, the accumulation of SOC, TN, and TP was greater than in swamp meadow and typical meadow because primary production exceeds the slow mineralization rates caused by permanent or temporary anaerobiosis associated with waterlogged conditions (Nieder and Benbi, 2008). Second, other factors that covaried with leaf and litter quality may have been more important drivers of soil properties. For example, the results of our study support the fact that greater litter diversity associated with species diversity (in typical meadow) can stimulate a large and active soil microbial community, which further results in higher rates of litter decomposition and higher soil nutrient availability (Wardle et al., 2006). In addition, in this study, fast-growing species (with higher SLA and LA) that produce high-quality litter may exceed slowgrowing species (with higher LDMC), which produce a litter of lower quality, therefore yielding the higher rates of litter decomposition in swamp meadow and typical meadow. Some ecosystem model studies such as BIOME-BGC (Running and Hunt, 1993) or CENTURY (Parton et al., 1993) also suggest that some key functional traits, such as SLA, LDMC, LA, and MPH, can directly affect ecosystem properties. Additionally, effects of plant functional traits on soil proper- ties may also result in positive or negative feedback effects, which influence plant community dynamics and composition (McLaren, 2006). In this study, higher soil available nutrients changed plant community structure and productivity to favor graminoid species, which have greater competitive and colonization abilities (e.g., K. capilifolia, E. nutans, P. poophagorum), over forb species in typical meadow (Moretto and Distel, 1997; Van der Wal et al., 2004; Li et al., 2015b).

Our results showed that functional diversity had no measurable effect on soil properties. Many studies have found that functional diversity does not influence litter decomposition and nutrient cycling (Barantal et al., 2011; Schindler and Gessner, 2009). However, these studies typically use only one metric of functional diversity. Functional diversity is complex, and single metrics may not capture its effects (Mason et al., 2005). In this study, we used three metrics of functional diversity (FRic, FEve, and FDiv), yet we still did not find evidence for a relationship between functional diversity and soil properties. We found little evidence to support the diversity hypothesis, which would predict that trait diversity would lead to a greater efficiency of nutrient use. These results also suggested that functional diversity (traits taken in aggregate) may not be directly related to ecosystem functioning (Li et al., 2015a). Zuo et al. (2016) directly measured the relationship between plant functional traits and the $\mathrm{C}$ and $\mathrm{N}$ storage in plant, litter, root, and soil along a restoration gradient of sandy grassland in northern China, and their results showed that ecosystem $\mathrm{C}$ and $\mathrm{N}$ pools are primarily associated with the traits of the most abundant species in communities, thereby also supporting the biomass ratio hypothesis. Overall, these results suggest that soil properties are likely to be predictable based on plant functional traits and/or litter quality, but not functional diversity. However, predicting soil properties from plant functional traits is likely to be a complex process.

\section{Conclusions}

Our study has demonstrated that simple, quantitative plant functional traits, but not functional diversity, could provide relevant information on key aspects of ecosystem functioning. We have also shown that the particular traits selected here, specific leaf area, leaf dry matter content, leaf area, and mature plant height, could be used to capture the functioning of plant species and communities. Our observations also promote a better understanding of plant-soil feedbacks related to plant functional traits in plant communities, but longterm monitoring is needed in future research, especially in different times of the year, because the cycling and sequestration of soil nutrients may be a "fast-out, slow-in" process with high variation due to regulation by environmental factors (Schulze, 2006). 


\section{Data availability}

The data are not publicly available due to copyright issues.

Competing interests. The authors declare that they have no conflict of interest.

Acknowledgements. This study was supported by the Natural Science Foundation of China (41601586, 41671289, 41230852), Natural Science Foundation of Shaanxi Province (2016JQ3008), State's Key Project of Research and Development Plan (2016YFC050704), Northwest A \& F University (QN2013069), and the Key Cultivation Project of the Chinese Academy of Sciences - the promotion and management of ecosystem functions of restored vegetation on the Loess Plateau, China.

Edited by: M. Oliva

Reviewed by: M. Ma and one anonymous referee

\section{References}

Barantal, S., Roy, J., Fromin, N., Schimann, H., and Hattenschwiler, S.: Long-term presence of tree species but not chemical diversity affect litter mixture effects on decomposition in a neotropical rainforest, Oecologia, 167, 241-252, 2011.

Cai, D. and Guo, N.: Dynamics monitoring of wetland in Maqu by means of remote sensing, IEEE Int. Geosci. Remote Sens. Symposium, 4603-4606, 2007.

Chen, L. Z. and Wang, Z. W.: The impacts of human alteration on ecosystem and diversity, Scientific Technology Press, Zhejiang, China, 1999.

Chesson, P.: Mechanisms of maintenance of species diversity, Annu. Rev. Ecol. Syst., 31, 343-366, 2000.

Cornelissen, J. H., Lavorel, S., Garnier, E., Díaz, S., Buch-mann, N., Gurvich, D. E., Reich, P. B., ter Steege, H., Morgan, H. D., van der Heijden, M. G. A., Pausas, J. G., and Poorter, H.: A handbook of protocols for standardised and easy measurement of plant functional traits worldwide, Aust. J. Bot., 51, 335-380, 2003

Cornelissen, J. H. C., Perez-Harguindeguy, N., Diaz, S., Grime, J. P., Marzano, B., Cabido, M., Vendramini, F., and Cerabolini, B.: Leaf structure and defence control litter decomposition rate across species and life forms in regional floras on two continents, New Phytol., 143, 191-200, 1999.

Denef, K., Six, J., Bossuyt, H., Frey, S. D., Elliott, E. T., Merckx, R., and Paustian, K.: Influence of dry-wet cycles on the interrelationship between aggregate, particulate organic matter, and microbial community dynamics, Soil Biol. Biochem., 33, 1599_ $1611,2001$.

Díaz, S. and Cabido, M.: Vive la différence: Plant functional diversity matters to ecosystem processes, Trends Ecol. Evol., 16, 646-655, 2001.

Diaz, S., Hodgson, J. G., Thompson, K., Cabido, M., Cornelissen, J. H. C., Jalili, A., Montserrat-Marti, G., Grime, J. P., Zarrinkamar, F., Asri, Y., Band, S. R., Basconcelo, S., Castro-Díez, P.,
Funes, G., Hamzehee, B., Khoshnevi, M., Pérez-Harguindeguy, N., Pérez-Rontomé, M. C., Shirvany, F. A., Vendramini, F., Yazdani, S., Abbas-Azimi, R., Bogaard, A., Boustani, S., Charles, M., Dehghan, M., de Torres-Espuny, L., FalczukV, GuerreroCampo, J., Hynd, A,. Jones, G., Kowsary, E., Kazemi-Saeed, F. Maestro-Martínez, M., Romo-Díez, A., Shaw, S., Siavash, B., Villar-Salvador, P., and Zak, M. R.: The plant traits that drive ecosystems: evidence from three continents, J. Veg. Sci., 15, 295-304, 2004.

Diaz, S., Lavorel, S., de Bello, F., Quetier, F., Grigulis, K., and Robson, T. M.: Land change science special feature: incorporating plant functional diversity effects in ecosystem service assessments, P. Natl. Acad. Sci. USA, 104, 20684-20689, 2007.

Garnier, E., Cortez, J., Billes, G., Navas, M. L., Roumet, C., Debussche, M., Laurent, G., Blanchard, A., Aubry, D., Bellmann, A., Neill, C., and Toussaint, J. P.: Plant functional markers capture ecosystem properties during secondary succession, Ecology, 85, 2630-2637, 2004

Gong, P., Niu, Z. G., Cheng, X., Zhao, K. Y., Zhou, D. Y., Guo, J. H., Liang, L., Wang, X. F., Li, D. D., Huang, H. B., Wang, Y., Wang, K., Li, W. N., Wang, X. W., Ying, Q., Yang, Z. Z., Ye, Y. F., Li, Z., Zhuang, D. F., Chi, Y. B., Zhou, H. Z., and Yan, J.: China's wetland change (1990-2000) determined by remote sensing, Science of China Series D: Earth Science, 53, 10361042, 2010.

Grime, J. P.: Evidence for existence of 3 primary strategies in plants and its relevance to ecological and evolutionary theory, Am. Nat., 111, 1169-1194, 1977.

Grime, J. P.: Benefits of plant diversity to ecosystems: immediate, filter and founder effects, J. Ecol., 86, 902-910, 1998.

Hautier, Y., Niklaus, P. A., and Hector, A.: Competition for light causes plant biodiversity loss after eutrophication, Science, 324 636-638, 2009.

He, S. and Richards, K.: Impact of Meadow Degradation on Soil Water Status and Pasture Management-A Case Study in Tibet, Land Degrad. Dev., 26, 468-479, 2015.

Hille Ris Lambers, J., Adler, P. B., Harpole, W. S., Levine, J., and Mayfield, M.: Rethinking community assembly through the lens of coexistence theory, Annu. Rev. Ecol. Evol. S., 43, 227-248, 2012.

Kalembasa, S. J. and Jenkinson, D. S.: A comparative study of titrimetric and gravimetric methods for the determination of organic carbon in soil, J. Sci. Food Agr., 24, 1085-1090, 1973.

Laughlin, D. C.: Nitrification is linked to dominant leaf traits rather than functional diversity, J. Ecol., 99, 1091-1099, 2011.

Lavorel, S. and Garnier, E.: Predicting changes in community composition and ecosystem functioning from plant traits: revisiting the Holy Grail, Funct. Ecol., 16, 545-556, 2002.

Li, W., Wen, S. J., Hu, W. X., and Du, G. Z.: Root-shoot competition interactions cause diversity loss after fertilization: a field experiment in an alpine meadow on the Tibetan Plateau, J. Plant Ecol., 4, 138-146, 2011a.

Li, W., Huang, H. Z., Zhang, Z. N., and Wu, G. L.: Effects of grazing on the soil properties and $\mathrm{C}$ and $\mathrm{N}$ storage in relation to biomass allocation in an alpine meadow, J. Soil Sci. Plant Nut., 11, 27-39, 2011b.

Li, W., Cheng, J. M., Yu, K. L., Epstein, H. E., Guo, L., Jing, G. H., Zhao, J., and Du, G. Z.: Plant functional diversity can be independent of species diversity: observations based on the impact of 
4-yrs of nitrogen and phosphorus additions in an alpine meadow, Plos One 10, e0136040, doi:10.1371/journal.pone.0136040, 2015a.

Li, W., Cheng, J. M., Yu, K. L., Epstein, H. E., and Du, G. Z.: Shortterm responses of an alpine meadow community to removal of a dominant species along a fertilization gradient, J. Plant Ecol., 8, 513-522, 2015b.

Lin, L., Li, Y. K., Xu, X. L., Zhang, F. W., Du, Y. G., Liu, S. L., Guo, X. W., and Cao, G. M.: Predicting parameters of degradation succession processes of Tibetan Kobresia grasslands, Solid Earth, 6, 1237-1246, doi:10.5194/se-6-1237-2015, 2015.

Loreau, M.: Biodiversity and ecosystem functioning: recent theoretical advances, Oikos, 91, 3-17, 2000.

Lu, X., Yan, Y., Sun, J., Zhang, X., Chen, Y., Wang, X., and Cheng, G.: Short-term grazing exclusion has no impact on soil properties and nutrients of degraded alpine grassland in Tibet, China, Solid Earth, 6, 1195-1205, doi:10.5194/se-6-1195-2015, 2015.

Luo, Y. J., Qin, G. L., and Du, G. Z.: Importance of assemblagelevel thinning: a field experiment in an alpine meadow on the Tibet plateau, J. Veg. Sci., 17, 417-24, 2006.

Ma, M., Ma, Z., and Du, G. Z.: Effects of water level on three wetlands soil seed banks on the Tibetan Plateau, Plos One, 9, e101458, doi:10.1371/journal.pone.0101458, 2014.

Mason, N. W. H., Mouillot, D., Lee, W. G., and Wilson, J. B.: Functional richness, functional evenness and functional divergence: the primary components of functional diversity, Oikos, 111, 112$118,2005$.

McGill, B. J., Enquist, B. J., Weiher, E., and Westoby, M.: Rebuilding community ecology from functional traits, Trends Ecol. Evol., 21, 178-185, 2006.

McLaren, J. R.: Effects of plant functional groups on vegetation dynamics and ecosystem properties, Arctic, 59, 449-451, 2006.

Miller, R. H. and Keeney, D. R.: Methods of soil analysis, 2nd Edn. Part 2, Chemical and Microbiological Properties, ASA, SSSA, Madison, WI, 1-129, 1982.

Moretto, A. S. and Distel, R. A.: Competitive interactions between palatable and unpalatable grasses native to a temperate semiarid grassland of Argentina, Plant Ecol., 130, 155-161, 1997.

Mouchet, M. A., Villéger, S., Mason, N. W. H., and Mouillot, D.: Functional diversity measures: an overview of their redundancy and their ability to discriminate community assembly rules, Funct. Ecol., 24, 867-876, 2010.

Nelson, D. W. and Sommers, L. E.: Total carbon, organic carbon and organic matter, in: Methods of Soil Analysis, edited by: Page, A. L., Miller, R. H., and Keeney, D. R., Part 2, Chemical and Microbiological Properties Agronomy Monograph, 2nd Edn., American Society of Agronomy Inc., Madison, 9, 539-579, 1982.

Nieder, R. and Benbi, D. K.: Carbon and Nitrogen in the Terrestrial Environment, Springer Science, 2008.

Niu, K. C., He, J. S., Zhang, S. T., and Lechowicz, M. J.: Grazing increases functional richness but not functional divergence in Tibetan alpine meadow plant communities, Biodivers. Conserv., 25, 2441, doi:10.1007/s10531-015-0960-2, 2015.

Parton, W. J., Scurlock, J. M. O., Ojima, D. S., Gilmanov, T. G., Scholes, R. J., Schimel, D. S., Kirchner, T., Menaut, J. C., Seastedt, T., Garcia, Moya, E., Apinan, K., and Kinyamario J. I.: Observations and modeling of biomass and soil organic matter dynamics for the grassland biome worldwide, Global Biogeochem. Cy., 7, 785-809, 1993.
Peng, F., Quangang, Y., Xue, X., Guo, J., and Wang, T.: Effects of rodent-induced land degradation on ecosystem carbon fluxes in an alpine meadow in the Qinghai-Tibet Plateau, China, Solid Earth, 6, 303-310, doi:10.5194/se-6-303-2015, 2015.

Pérez, F., Hinojosa, L. F., Ossa, C. G., Campano, F., and Orrego, F.: Decoupled evolution of foliar freezing resistance, temperature niche and morphological leaf traits in Chilean Myrceugenia, J. Ecol., 102, 972-980, 2014.

Perez-Harguindeguy, N., Diaz, S., Garnier, E., Lavorel, S., Poorter, H., Jaureguiberry, P., BretHarte, M., Cornwell, W., Craine, J., Gurvich, D., Urcelay, C., Veneklaas, E., Reich, P., Poorter, L., Wright, I., Ray, P., Enrico, L., Pausas, J., de Vos, A., Buchmann, N., Funes, G., Quetier, F., Hodgson, J., Thompson, K., Morgan, H., ter Steege, H., van der Heijden, M., Sack, L., Blonder, B., Poschlod, P., Vaieretti, M., Conti, G., Staver, A., Aquino, S., and Cornelissen J.: New handbook for standardised measurement of plant functional traits worldwide, Aust. J. Bot, 61, 167-234, 2013.

Pielou, E. C.: An introduction to mathematical ecology, New York, Wiley, 1969.

Poorter, H. and Garnier, E.: The ecological significance of variation in relative growth rate and its components, in: Handbook of plant functional ecology, edited by: Pugnaire, F. and Valladares, F., New York, Marcel Dekker, 1999.

Pulleman, M. and Tietema, A.: Microbial C and N transformations during drying and rewetting of coniferous forest floor material, Soil Biol. Biochem., 31, 275-285, 1999.

Quétier, F., Thébault, A., and Lavorel, S. Plant traits in a state and transition framework as markers of ecosystem response to past and present land use in subalpine grasslands, Ecol. Monogr., 77, 32-52, 2007.

Reich, P. B.: The world-wide "fast-slow" plant economics spectrum: a traits manifesto, J. Ecol., 102, 275-301, 2014.

Reich, P. B., Ellsworth, D. S., Walters, M. B., Vose, M. J., Gresham, C., Volin, J. C., and Bowman, W. D.: Generality of leaf trait relationships: a test across six biomes, Ecology, 80, 1955-1969, 1999.

Robson, T. M., Lavorel, S., Clement, J. C., and Le Roux, X. Neglect of mowing and manuring leads to slower nitrogen cycling in subalpine grasslands, Soil Biol. Biochem., 39, 930-941, 2007.

Running, S. W. and Hunt, E. R. Generalization of a forest ecosystem process model for other biomes, BI-OME-BGC, and an application for global-scale models, in: Scaling physiological processes, Leaf to globe, edited by: Ehleringer, J. R. and Field, C. B., Academic Press, San Diego, California, USA, 141-158, 1993.

Schindler, M. H. and Gessner, M. O.: Functional leaf traits and biodiversity effects on litter decomposition in a stream, Ecology, 90, 1641-1649, 2009.

Schulze, E.-D.: Biological control of the terrestrial carbon sink, Biogeosciences, 3, 147-166, doi:10.5194/bg-3-147-2006, 2006.

Shipley, B. and Lechowicz, M. J.: The functional coordination of leaf morphology and gas exchange in 40 wetland plant species, Ecoscience, 7, 183-194, 2000.

Shipley, B., Lechowicz, M. J., Wright, I., and Reich, P. B.: Fundamental trade-offs generating the worldwide leaf economics spectrum, Ecology, 87, 535-541, 2006.

Suding, K. N., Lavorel, S., Chapin, F. S., Cornelissen, J. H. S., Diaz, S., Garnier, E., Goldberg, D., Hooper, D., Jackson, S., and Navas, M. L.: Scaling environmental change through the community- 
level: a trait-based response-and-effect framework for plants, Glob. Change Biol., 14, 1125-1140, 2008.

Tilman, D., Knops, J., Wedin, D., Reich, P., Ritchie, M., and Siemann, E.: The influence of functional diversity and composition on ecosystem processes, Science, 277, 1300-1302, 1997.

Van der Wal, R., Bardgett, R. D., Harrison, K. A., and Stien, A.: Vertebrate herbivores and ecosystem control: cascading effects on tundra ecosystems, Ecography, 27, 242-252, 2004.

Villéger, S., Mason, N. W. H., and Mouillot, D.: New multidimensional functional diversity indices for a multifaceted framework in functional ecology, Ecology, 89, 2290-2301, 2008.

Wang, C., Wang, G., Wang, Y., Rafique, R., Ma, L., Hu, L., and Luo, Y.: Fire alters vegetation and soil microbial community in Alpine Meadow, Land Degrad. Dev., 27, 1379-1390, 2016.

Wardle, D. A., Yeates, G. W., Barker, G. W., and Bonner, K. I.: The influence of plant litter diversity on decomposer abundance and diversity, Soil Biol. Biochem., 38, 1052-1062, 2006.

Westoby, M., Falster, D. S., Moles, A. T., Vesk, P. A., and Wright, I. J.: Plant ecological strategies: some leading dimensions of variation between species, Annu. Rev. Ecol. Syst., 33, 125-159, 2002.
Wright, I. J., Reich, P. B., and Westoby, M.: Strategy shifts in leaf physiology, structure and nutrient content between species of high- and low-rainfall and high- and low-nutrient habitats, Funct. Ecol. 15, 423-434, 2001.

Wright, I. J., Reich, P. B., Westoby, M., Ackerly, D. D., Baruch, Z., Bongers, F., Cavender-Bares, J., Chapin, F. S., Cornelissen, J. H. C., Diemer, M., Flexas, J., Garnier, E., Groom, P. K., Gulias, J., Hikosaka, K., Lamont, B. B., Lee, T., Lee, W., Lusk, C., Midgley, J. J., Navas, M.L ., Niinemets, Ü., Oleksyn, J., Osada, N., Tjoelker, M. G., Veneklaas, E., and Villar, R.: The worldwide leaf economics spectrum, Nature, 428, 821-827, 2004.

Yu, Y. and Jia, Z. Q.: Changes in soil organic carbon and nitrogen capacities of Salix cheilophila Schneid along a revegetation chronosequence in semi-arid degraded sandy land of the Gonghe Basin, Tibet Plateau, Solid Earth, 5, 1045-1054, doi:10.5194/se5-1045-2014, 2014.

Zuo, X. A., Zhou, X., Peng, L., Zhao, X. Y., Zhang, J., Wang, S. K., and Yue, X. Y.: Testing associations of plant functional diversity with carbon and nitrogen storage along a restoration gradient of sandy grassland, Front. Plant Sci., 7, 1-11, 2016. 